\title{
Spontaneous Regression of Congenital Posterior Fossa Lesion Radiologically Mimicking Teratoma - Case Report
}

\author{
Khursheed Ahmad Ansari ${ }^{*}, 1$, Bejoy Thomas ${ }^{2}$, Easwer HV ${ }^{3}$ and Suresh Nair ${ }^{3}$ \\ ${ }^{1}$ Wockhardt Hospitals, The Umrao Institute of Medical Sciences and Research, Mira road, North Bombay, 401107 India \\ ${ }^{2}$ Department of Radiology, Sree Chitra Tirunal Institute for Medical Sciences and Technology, Trivandrum,Kerala, \\ 695011 India \\ ${ }^{3}$ Department of Neurosurgery, Sree Chitra Tirunal Institute for Medical Sciences and Technology, Trivandrum, Kerala, \\ 695011 India
}

\begin{abstract}
We report a case of spontaneous regression of a congenital intracranial lesion presumed to be a teratoma. Various radiological features of teratoma mentioned in the literature are vague complex echogenic mass on prenatal ultrasonography, clump like calcification on CT scan, usual size being more than $5 \mathrm{~cm}$, suprasellar and pineal region location. Radiological features of this lesion were consistent with teratoma. The child was managed conservatively with oral steroids as an antiedema measure. Follow up scans over 2years showed more than $80 \%$ regression in size of the lesion. This is the first reported case of presumed teratoma, on radiological imaging that regressed spontaneously.
\end{abstract}

Keywords: Calcification, regression, teratoma.

\section{INTRODUCTION}

Most of the neoplasms detected at birth or during the first month of life have their beginning in the intrauterine period. It comprises of $2.5 \%$ of all tumors in the pediatric age group [1]. Teratomas are the commonest tumors in this group [2,3]. They are usually sporadic with some cases diagnosed antenatally. The outcomes of such lesions are generally poor, though surgical resection, if possible may give long term survival benefit [4]. However there is no case report so far, mentioning spontaneous regression of such congenital intracranial lesions. We report a case where spontaneous regression of congenital intracranial lesion radiologically resembling a teratoma occurred.

\section{CASE REPORT}

A one-month old male child presented to us with the complaint of large head-size and an episode of tonic posturing fifteen days before. Prenatal Ultrasound done at 36 weeks of gestation revealed large featal head with dilated ventricular system. Anticipating cephalo-pelvic disproportion an elective Caesarean section was done. Apgar score was normal at birth. The birth weight was $2.8 \mathrm{~kg}$ and his head circumference was $40 \mathrm{~cm}$ at birth (macrocephaly for his age). Child had normal sucking reflex. There was no history of poor feeding, irritability, excessive crying, recurrent vomiting, failure to thrive or excessive sleep. On

\footnotetext{
*Address correspondence to this author at the Wockhardt Hospitals, The Umrao Institute of Medical Sciences and Research, Mira Road, North Bombay, India - 401107; Tel: +919699674595;

E-mail: drkhursheed@ rediffmail.com
}

examination, his head circumference was $42 \mathrm{~cm}$ (which was greater than 2SD expected for his age), and anterior fontanelle was open and full. His general physical examination was unremarkable. Child was alert, playful and had good cry with no discernible neurological deficit.

Retrospective evaluation of prenatal ultrasonography images done at 36 weeks of gestational age (Fig. 1A) showed a complex echogenic mass with hydrocephalus.

CT scan of brain at the age of 1 month (Fig. 1B) was done at the referred hospital which showed a large heterogeneous predominantly hypo-dense lesion $(4.6 \mathrm{~cm} \times 5.6 \mathrm{~cm} \times 5.7 \mathrm{~cm})$ with chunks of calcification located in posterior fossa. It was extending from pineal region to occipital convexity. There

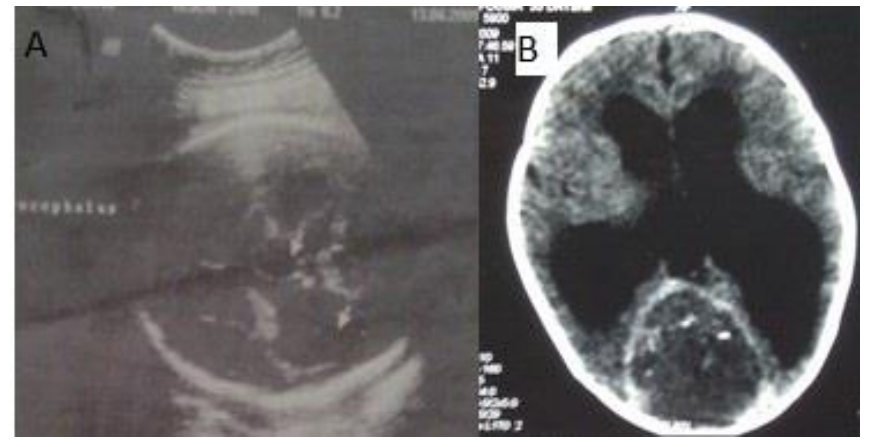

Fig. (1). A: Ultrasonography at 36 weeks of gestation showing large fetal head with dilated ventricular system (white arrow). B: Contrast enhanced CT scan brain showing large heterogenous density lesion with clump like areas of calcification. Hydrocephalus is evident with gross ventriculomegaly. 
was gross dilatation of ventricles. The parents were explained about the nature of disease, as well as the pros and cons of surgical intervention. They preferred not to subject their child to surgery. The child was discharged on a tapering dose of steroids. He was maintained on periodic follow up during which the child remained asymptomatic and attained all milestones expected for his age.

At the end of one year the infant was evaluated with MRI brain to know the status of lesion (Fig. 2A). A well-defined heterogenous extra axial lesion was noted on MRI in the region of torcula Herophili. There were small areas of blooming within the lesion as well as in the adjacent occipital lobe and cerebellar hemisphere on susceptibility weighted images. On post contrast study there was minimal enhancement, more towards the periphery of the lesion. There was evidence of reduction in size of the lesion, although asymptomatic ventriculomegaly persisted.

He remained free from symptoms at 2 year of age when a CT scan of the head was done which showed further regression of the lesion (Fig. 2B).

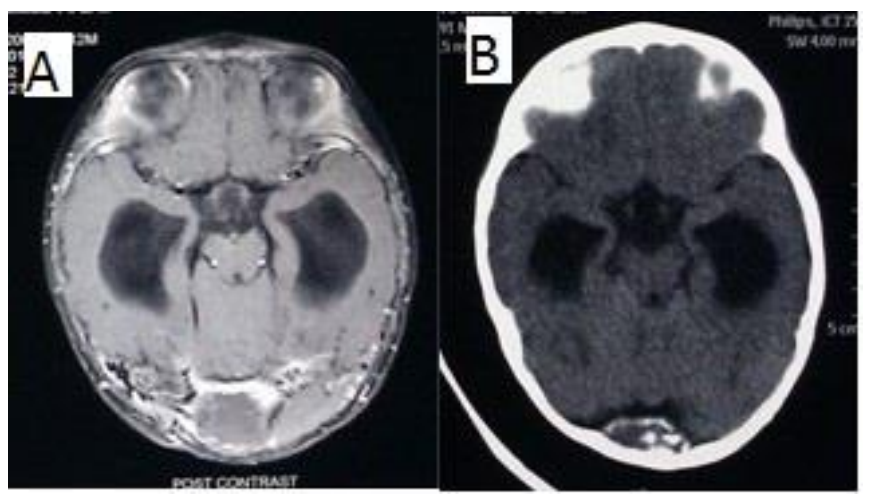

Fig. (2). A: T1W contrast axial image showing significant reduction in size of the lesion. B: Plain CT scan brain showing remnant of regressed lesion.

\section{DISCUSSION}

We report a unique case of a lesion which radiologically seems to be a teratoma and showed features of regression on serial neuroimaging. Congenital intracranial tumors are rare and only account for $0.5 \%$ to $1.5 \%$ of all childhood brain tumors [5-7]. Various intracranial tumors presenting in neonates reported in literature in order of frequency are as follows - Glial tumor (includes astrocytoma, glioblastoma, choroid plexus papilloma and ependymoma), teratomas, PNETs and rarely, medulloblastoma, ganglioglioma, meningeal neoplasms [8]. Among the tumors present at birth, teratomas account for $28.8 \%$ to $50 \%$ of central nervous system (CNS) tumors [9]. They are usually detected during prenatal period as complex echogenic masses as compared to hypoechoic medulloblastoma and hyperechoic angioblastic meningioma [8]. On CT scan, teratomas usually show clump like calcification [8], and measure more than $5 \mathrm{~cm}$ in diameter [5]. The radiological feature of this lesion thus favored a teratoma, owing to its presence in the prenatal ultrasonography, clumped calcification as well as its size, and location at pineal region. Another feature that favors teratoma is its extra axial location unlike - medulloblastoma, PNET, choroid plexus papilloma. Most teratomas are midline tumors located predominantly in the sellar and pineal regions [10]. There are case reports describing teratoma occuring at other locations e.g. lateral ventricle [11]. The prognosis of congenital intracranial teratomas have been poor as these lesions are extensive when they are identified.

Spontaneous regression of malignant tumors have been seen generally in one of 60,000 to 100,000 patients [12] There have been sporadic reports of this phenomenon of intracranial tumors identified radiologically, and this list includes intracranial metastasis of renal cell carcinoma [13], malignant lymphoma $[14,15]$ and glioma associated with neurofibromatosis [16,17].

The possible mechanisms that have been suggested for this phenomenon include an immunological (cell mediated and humoral) mechanism, bacterial or viral infection, apoptosis, and surgical or other trauma [18,19]. Of these mechanisms, apoptosis is thought to play a role in most spontaneous regressions involving neoplasms, and an apoptosis-triggered immunological response is thought to be the main effector mechanism [20]. Corticosteroid treatment may change the patient's total immunological defense mechanism, which then is sufficient to eradicate the intracranial tumor [13,21]. In our case too patient had received a tapering dose of steroids. Spontaneous regression is known to occur in patients with seminomas [22], however there wasn't any report showing regression of congenital teratomas spontaneously. Histological confirmation would have been desirable to confirm the radiolgical diagnosis.

\section{CONCLUSION}

This case report highlights a very aggressive congenital lesion detected on imaging which mimicked a teratoma radiolgically, However, histological confirmation would have been desirable to confirm the precise nature of the lesion.

\section{CONFLICT OF INTEREST}

The authors confirm that this article content has no conflicts of interest.

\section{ACKNOWLEDGEMENTS}

Declared none.

\section{REFERENCES}

[1] Isaac H Jr. Perinatal (congenital and neonatal) neoplasms: A report of 110 cases. Pediatr Pathol 1985; 3: 165-216.

[2] Takaku A, Kdama N, Ohara H, Hri S. Brain tumor in newborn babies. Child's Brain 1978; 4: 365-75.

[3] Wakai S, Arai T, Nagai M. Congenital brain tumors. Surg Neurol 1984; 21: 597-609.

[4] Lanzino G, Kaptain GJ, Jane JA, et al. Successful excision of a large immature teratoma involving the cranial base: report of a case with long-term follow-up. Neurosurgery 1998; 42: 389-93.

[5] Jänisch W. Brain tumors in the infancy. J Neuropathol Exp Neurol 1995; 54[Suppl]: 55S-56S.

[6] Balestrini MR, Micheli R, Giordano L, Lasio G, Giombini S. Brain tumors with symptomatic onset in the first two years of life. Child's Nerv Syst 1994; 10: 104-10.

[7] Jooma R, Kendall BE. Intracranial tumours in the first year of life. Neuroradiology 1982; 23: 267-74. 
[8] Buetow PC, Smirnitpoulos JG, Done S. Congenital brain tumors: a reviews of 45 cases. Am J Roentgenol 1990; 155: 587-93.

[9] Rickert CH, Probst-Cousin S, Louwen F, Feldt B, Gullotta F. Congenital immature teratoma of the fetal brain. Childs Nerv Syst 1997; 13: 556-9.

[10] Jennings MT, Gelman R, Hochberg F. Intracranial germ-cell tumors: natural history and pathogenesis. J Neursurg 1985; 63: 155-65.

[11] Arslan E, Usul H, Baykal S, Acar E, Eyüboğlu EE, Reis A. Massive congenital intracranial immature teratoma of the lateral ventricle with retro-orbital extension: a case report and review of the literature. Pediatr Neursurg 2007; 43: 338-42.

[12] Cole WH. Efforts to explain spontaneous regression of cancer. J Surg Oncol 1981; 17: 201-9.

[13] Omland H, Fossa SD. Spontaneous regression of cerebral and pulmonary metastasis in renal cell carcinoma. Scand $\mathrm{J}$ Urol Nephrol 1989; 23: 159-60.

[14] Sonoba H, Matsukado Y, Kaku M. Peculiar characteristics of primary intracranial malignant lymphoma. Report of three cases. Neuro Med Chir 1983; 23: 483-9.
[15] Sugita Y, Shigemori M, Yuge T, et al. Spontaneous regression of primary malignant intracranial lymphoma. Surg Neurol 1988; 30: 148-52.

[16] Brzowski AE, Bazan C III, Mumma JV, Rayan SG. Spontaneous regression of optic glioma in a patient with neurofibromatosis. Neurology 1992; 42: 679-81.

[17] Leisti EL, Pyhinen J, Poyhonen M. Spontaneous decrease of a pilocytic astrocytoma in a neurofibromatosis type I. Am J Neurorodiol 1996; 17: 1691-4.

[18] Lam KC, Ho JCI, Yeung RTT. Spontaneous regression of hepatocellular carcinoma. A case study. Cancer 1982; 50: 332-6.

[19] Park SK, Brody JI, Wallace HA, Blakemore WS Immunosuppressive effect of surgery. Lancet 1971; 1: 53-5.

[20] Kaeser HE. Bodey B Jr, Siegel SE, Gröger AM, Bodey B. Spontaneous neoplastic regression: The significance of apoptosis. In vivo 2000; 14: 773-8.

[21] Williams RS, Crowell RM, Fisher CM, et al. Clinical and radiologic remission in reticulum cell sarcoma of the brain. Arch Neurol 1979; 36: 206-10.

[22] Holmes AS, Klimberg IW, Stonesiefer KJ, Kramer BS, Waisman Z. Spontaneous regression of testicular seminoma: case report. J Urol 1986; 135: 795-6.

(C) Ansari et al.; Licensee Bentham Open.

This is an open access article licensed under the terms of the Creative Commons Attribution Non-Commercial License (http://creativecommons.org/licenses/by-nc/3.0/) which permits unrestricted, non-commercial use, distribution and reproduction in any medium, provided the work is properly cited. 